\title{
The best laid schemes of airway repair
}

\author{
Emma L. Rawlins ${ }^{1}$ and Adam Giangreco ${ }^{2}$ \\ Affiliations: 'Gurdon Institute, University of Cambridge, Cambridge, UK. ${ }^{2}$ Lungs for Living Research Centre,
} University College London, London, UK.

Correspondence: Adam Giangreco, Lungs for Living Research Centre, Division of Medicine, 5 University Street, London, WC1E 6JF, UK. E-mail: a.giangrecoQucl.ac.uk

The best-laid schemes o' mice an' men

Gang aft agley,

An' lea'e us nought but grief an' pain,

For promis'd joy!

Still thou are blest, compared wi' me!

The present only toucheth thee:

But och! I backward cast my e'e,

On prospects drear!

An' forward, tho' I canna see,

I guess an' fear!

Excerpt from "To a Mouse" by Robert Burns

Two recent studies have provided new insights into the cellular identity and preferred regenerative schemes of progenitor cells in mouse and human airways $[1,2]$. These findings not only have important implications for disease progression, but may also help scientists develop new techniques for improving human airway regeneration.

\section{Schemes of homeostasis and repair}

The mouse trachea is lined by basal, secretory and ciliated cells. Previous genetic lineage tracing studies have shown that in the homeostatic and repairing mouse trachea, basal cells are widespread, multipotent progenitor cells capable of both long-term self-renewal and differentiation into ciliated and secretory cells [3, 4]. Similar experiments have also shown that differentiated tracheal club cell (Clara cell) secretory protein (CCSP)expressing cells can also self renew and give rise to ciliated cells, but that these do not play a major role in tracheal homeostasis [5]. In a recent publication, TATA et al. [1] found that murine airways exhibit an unexpected cellular plasticity in response to genetically mediated basal progenitor cell ablation. Lineage labelling showed that tracheal CCSP-expressing cells can differentiate into fully functional basal cells competent to act as epithelial progenitors. This alternate strategy of CCSP-expressing cell-mediated repair of the tracheal epithelium was also replicated in vitro, suggesting that contact-mediated signalling between airway basal cells and CCSP-expressing cells is required to prevent CCSP-expressing cells dedifferentiating to basal progenitor cells in homeostatic airways. The Notch and Egfr intercellular signalling pathways, or those of other surface receptors, such as cadherins, are candidates to mediate such a signal [6-8].

0

@ERSpublications

Considering the relevance of exciting new findings on mouse respiratory stem cells to human health http://ow.ly/xwn7J

Received: March 142014 | Accepted after revision: May 272014

Conflict of interest: None declared.

Copyright @ERS 2014 
This work illustrates how flexible stem/progenitor cell hierarchies can be in response to injury. Loss of the preferred progenitor cell type (basal cells) provides an inductive cue to remaining cells to dedifferentiate and initiate airway repair. Similar findings have also recently been reported in more established stem cell hierarchies including the intestinal crypt $[9,10]$. It is plausible that similar plasticity amongst cells of the distal airways and alveoli could reconcile many of the apparent contradictions amongst murine lineage tracing experiments in this region. Specifically, lineage labelling and chimeric analysis in mice have clearly demonstrated that at homeostasis, CCSPexpressing cells $[5,11]$ and type 2 pneumocytes $[12,13]$ are widespread epithelial progenitors in the smaller airways and alveoli. However, in response to different types and severities of injury, alternative progenitor cell populations that express both CCSP and surfactant protein C, as well as cells that express integrins $\alpha 6$ and $\beta 4$, and keratins 5 and 14, have also been identified [14-18]. At present, the cellular origin and precise identity of these keratin 5-expressing distal airway progenitor cells remains elusive. Future experiments, perhaps with a focus on potential lineage plasticity using multiple injury-repair models, will no doubt bring further clarity.

\section{Of mice and men}

The flexibility in schemes of murine airway homeostasis and regeneration are potentially important for regenerative medicine and in treating lung diseases such as cancer. But before these issues are examined, we need to know how similar the epithelial cell hierarchy is between mouse and human airways. In vitro studies using human cells have supported the hypothesis that, similar to those of mice, human basal cells are a multipotent airway epithelial progenitor [4, 19]. Independent in vivo studies by TeIXeIRA et al. [2] have taken advantage of naturally occurring mitochondrial mutations to perform quantitative analysis of stochastically occurring cell clones within intact human airways. Results of this study suggest that basal cells are a preferred multipotent progenitor cell in human airways, and that over time a natural process of clonal consolidation reduces the number of clonally distinct basal progenitor cell clones (fig. 1). Moreover, by comparing clone size and abundance in smokers versus nonsmokers, it appeared that the rate of clonal consolidation was accelerated in smokers, most likely due to the more rapid turnover of smokers' airways (fig. 1, red line). Whether one or multiple types of human basal cells are responsible for human airway homeostasis and clonal consolidation remains an open question. In either case, in human oral squamous cell carcinoma, it was recently shown that mitochondrial DNA mutations, which may be indicative of clonal consolidation, are associated with increased cancer recurrence and reduced patient survival [20]. These data suggest that further in vitro and in vivo investigations of basal cell clonal consolidation may be relevant in patients undergoing surgery for early stage lung cancer. The presence of extensive clonal consolidation may warrant more aggressive therapeutic interventions, such as adjuvant chemo- or radiotherapy, even in the absence of identifiable micro-metastases. Future studies are now required to address this possibility.

Interestingly, CCSP-expressing cells are virtually absent from proximal human airways [2]. This suggests that CCSP-expressing cells are unlikely to function as alternate progenitor cells in human upper airways. It is also unlikely that this difference between human and murine lungs simply reflects an underlying human lung pathology, as CCSP-expressing cells are absent in the airways of smokers and nonsmokers alike. Could other secretory cells, such as mucinous goblet cells, fulfil a multipotent progenitor cell role in a repair setting? Or do human airways lack the flexibility of progenitor cell choice that exists in murine lungs?

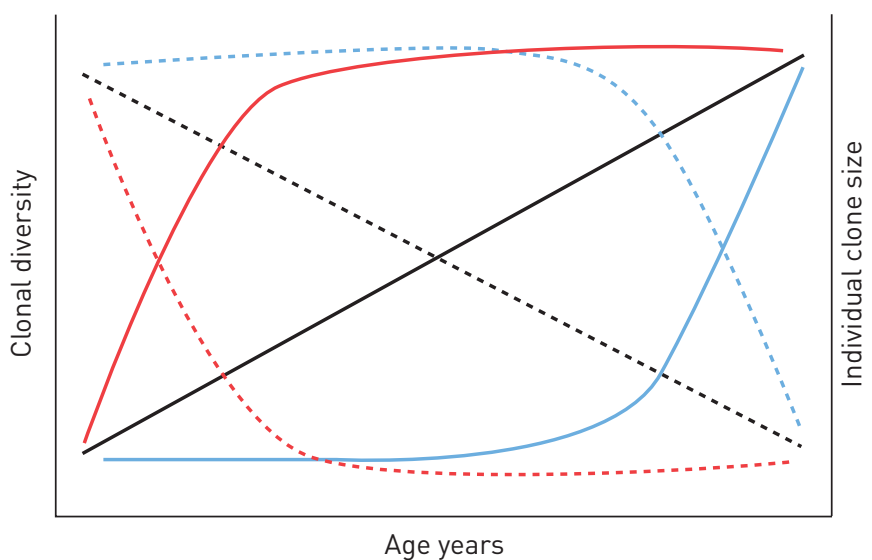

FIGURE 1 Ageing and clonal consolidation. As lungs age, a natural process of clonal consolidation results in reduced airway epithelial clonal diversity (- - - ) and increased individual clone size (_- ). In healthy individuals, it is currently unclear whether this process occurs predominantly in old age (blue lines) or continuously throughout life (black lines). In either case, evidence suggests that clonal consolidation is accelerated in the airways of smokers, resulting in a rapid loss of airway clonal diversity (red lines). 
Answering these questions is not merely academic, but has significant implications for both airway regenerative medicine and lung disease ontogeny. For example, if multiple airway progenitor cell types exist in human lungs, which are responsible for the initiation of lung diseases such as cancer? And which cell type would be most useful as a cellular therapy for lung regeneration?

\section{Forward, though we cannot see}

If the ultimate aim of this research is to develop new treatments for human lung disease, then understanding the contribution of the various stem and progenitor cells and their associated niches to lung pathology is of primary importance. This will undoubtedly require complementary approaches involving both clinically relevant animal systems and improved human models for studying lung repair and regeneration. Examples of human models are likely to include ex vivo lung perfusion and in vitro organoid models.

One immediate future direction of airway stem cell research, with potential for short- to medium-term clinical benefits, is investigating the possibility of links between tumour recurrence and airway regeneration. The incidence of lung cancer recurrence in patients with stage 1 (T1N0) disease following surgical lobectomy is $20-30 \%$ [21]. This high recurrence rate suggests that mutated cells capable of regenerating a tumour are frequently located outside of resectable tumour margins. This is consistent with the recent identification of widely dispersed, clonally related, preinvasive lung cancer cells located throughout the airways of many smokers [22]. Whether these cells have become intrinsically more progenitor- or stem-like, or whether their contribution to tumour growth is controlled extrinsically within permissive airway microenvironments (such as endogenous stem cell niches) remains unclear. In either case, it will be valuable to test the hypothesis that distinct airway microenvironments may extrinsically regulate airway progenitor cell fate in health and disease.

\section{References}

1 Tata PR, Mou H, Pardo-Saganta A, et al. Dedifferentiation of committed epithelial cells into stem cells in vivo. Nature 2013; 503: 218-223.

2 Teixeira VH, Nadarajan P, Graham TA, et al. Stochastic homeostasis in human airway epithelium is achieved by neutral competition of basal cell progenitors. Elife 2013; 2: e00966.

3 Hong KU, Reynolds SD, Watkins S, et al. In vivo differentiation potential of tracheal basal cells: evidence for multipotent and unipotent subpopulations. Am J Physiol Lung Cell Mol Physiol 2004; 286: L643-L649.

4 Rock JR, Onaitis MW, Rawlins EL, et al. Basal cells as stem cells of the mouse trachea and human airway epithelium. Proc Natl Acad Sci USA 2009; 106: 12771-12775.

5 Rawlins EL, Okubo T, Xue Y, et al. The role of Scgblal ${ }^{+}$Clara cells in the long-term maintenance and repair of lung airway, but not alveolar, epithelium. Cell Stem Cell 2009; 4: 525-534.

6 Rock JR, Gao X, Xue Y, et al. Notch-dependent differentiation of adult airway basal stem cells. Cell Stem Cell 2011; 8: 639-648.

7 Vermeer PD, Einwalter LA, Moninger TO, et al. Segregation of receptor and ligand regulates activation of epithelial growth factor receptor. Nature 2003; 422: 322-326.

8 Lu L, Teixeira VH, Yuan Z, et al. LRIG1 regulates cadherin-dependent contact inhibition directing epithelial homeostasis and pre-invasive squamous cell carcinoma development. J Pathol 2013; 229: 608-620.

9 Ritsma L, Ellenbroek SI, Zomer A, et al. Intestinal crypt homeostasis revealed at single-stem-cell level by in vivo live imaging. Nature 2014; 507: 632-365.

10 Buczacki SJ, Zecchini HI, Nicholson AM, et al. Intestinal label-retaining cells are secretory precursors expressing Lgr5. Nature 2013; 495: 65-69.

11 Giangreco A, Arwert EN, Rosewell IR, et al. Stem cells are dispensable for lung homeostasis but restore airways after injury. Proc Natl Acad Sci USA 2009; 106: 9286-9291.

12 Barkauskas CE, Cronce MJ, Rackley CR, et al. Type 2 alveolar cells are stem cells in adult lung. J Clin Invest 2013; 123: 3025-3036.

13 Desai TJ, Brownfield DG, Krasnow MA. Alveolar progenitor and stem cells in lung development, renewal and cancer. Nature 2014; 507: 190-194.

14 Zheng D, Limmon GV, Yin L, et al. Regeneration of alveolar type I and II cells from Scgbla1-expressing cells following severe pulmonary damage induced by bleomycin and influenza. PLoS One 2012; 7: e48451.

15 Chapman HA, Li X, Alexander JP, et al. Integrin $\alpha 6 \beta 4$ identifies an adult distal lung epithelial population with regenerative potential in mice. J Clin Invest 2011; 121: 2855-2862.

16 Kumar PA, Hu Y, Yamamoto Y, et al. Distal airway stem cells yield alveoli in vitro and during lung regeneration following H1N1 influenza infection. Cell 2011; 147: 525-538.

17 Rock JR, Barkauskas CE, Cronce MJ, et al. Multiple stromal populations contribute to pulmonary fibrosis without evidence for epithelial to mesenchymal transition. Proc Natl Acad Sci USA 2011; 108: E1475-E1483.

18 Tropea KA, Leder E, Aslam M, et al. Bronchioalveolar stem cells increase after mesenchymal stromal cell treatment in a mouse model of bronchopulmonary dysplasia. Am J Physiol Lung Cell Mol Physiol 2012; 302: L829-L837.

19 Hackett NR, Shaykhiev R, Walters MS, et al. The human airway epithelial basal cell transcriptome. PLoS One 2011; 6: e18378.

20 Lai CH, Huang SF, Liao CT, et al. Clinical significance in oral cavity squamous cell carcinoma of pathogenic somatic mitochondrial mutations. PLoS One 2013; 8: e65578.

21 Kelsey CR, Marks LB, Hollis D, et al. Local recurrence after surgery for early stage lung cancer: an 11-year experience with 975 patients. Cancer 2009; 115: 5218-5227.

22 Pipinikas CP, Kiropoulos TS, Teixeira VH, et al. Cell migration leads to spatially distinct but clonally related airway cancer precursors. Thorax 2014; 69: 548-557. 